\title{
ANALYSIS OF OFFENSIVE AND DEFENSIVE ACTIONS OF YOUNG SOCCER GOALKEEPERS
}

original paper

() Wroclaw University of Health and Sport Sciences

DOI: https://doi.org/10.5114/hm.2021.104183

\section{JOÃO SANTOS ${ }^{1}$, PAULO MALICO SOUSA ${ }^{1}$, VALTER PINHEIRO ${ }^{2}$, FERNANDO JORGE SANTOS ${ }^{3}$}

${ }^{1}$ Higher Institute of Educational Sciences (Instituto Superior de Ciências Educativas), Lisbon, Portugal

${ }^{2}$ Quality of Life Research Centre, Higher Institute of Educational Sciences (Instituto Superior de Ciências Educativas),

Lisbon, Portugal

${ }^{3}$ Quality of Life Research Centre, Polytechnic Institute of Setúbal, Setúbal, Portugal

\section{ABSTRACT}

Purpose. The study aimed to investigate the defensive and offensive technical-tactical actions of elite young football goalkeepers.

Methods. The goalkeepers who participated in our study ( $n=3$; mean age: 16.6 years) had 8 years of experience in the position, were Portuguese, and competed in the Portuguese National Championship U-17. Thirty championship games were observed. The observational instruments used were constructed and validated for the investigation, and the technicaltactical actions were coded with the Lince ${ }^{\circledR}$ software. The data were processed through a descriptive analysis, by using the Microsoft Excel ${ }^{\circledR}$ computer program.

Results. Defensive actions with most occurrences were goal defence (25.33 \pm 8.14), deviation to punch (13.67 \pm 12.5$)$, with 2 hands (45.66 \pm 21.38$)$, and in zone 1 (50.33 \pm 34.81$)$. Offensive actions started more frequently with delayed pass (38.33 \pm 28.01$)$, for zone 1 (28.7 \pm 20.60$)$. The goalkeepers executed goal kick most frequently (17.33 \pm 14.29$)$, followed by short hand replacement $(16.67 \pm 12.06)$ and short pass $(14.33 \pm 10.02)$. The preferred pass zone was $9(17.33 \pm 10.26)$, and actions sought to initiate positional attack $(86 \pm 61.02)$.

Conclusions. In the defensive process, the goalkeepers' actions are mostly focused on the objective of goal defence; in the offensive process, technical actions with the hands and feet are important in the participation in positional attack construction. Key words: football, goalkeeper, match, analysis, skills performance

\section{Introduction}

Performance analysis is key to collecting information about players and teams, helping the coach make decisions about training and competition [1]. This becomes relevant for the specific position of a goalkeeper, not only for training to meet their needs for evolution, but also with regard to the requirements relating to the team's play style [2]. In performance analysis, it is important to observe and analyse [3] in order to collect key information for the development of players and team through the training process, preparing them for the requirements of a competition [4]. Goalkeepers' performance differs substantially from that of other players who make up the team, which makes it important for specific coaches [5] to organize their observation and analysis, to differentiate the players' action in offensive and defensive moments [6, 7], to collect information relevant to the construction and planning of training exercises. One of the ways to make this analysis beneficial is through the notational analysis, which allows to evaluate the technical and tactical aspects and to compile a set of statistical data [8].

Some studies have been developed in order to understand the goalkeeper's actions in the defensive and offensive process. The goal defence is one of the most relevant actions in defensive terms, highlighting the effectiveness of goalkeepers in actions that stop goal

Correspondence address: Fernando Jorge Santos, Instituto Politécnico de Setúbal, Escola Superior de Educação,

Centro de Investigação em Qualidade de Vida, Campus do IPS, Estefanilha, 2914-504 Setúbal, Portugal,

e-mail: fjlsantos@gmail.com

Received: May 18, 2020

Accepted for publication: September 19, 2020

Citation: Santos J, Sousa PM, Pinheiro V, Santos FJ. Analysis of offensive and defensive actions of young soccer goalkeepers. Hum Mov. 2022;23(1):18-27; doi: https://doi.org/10.5114/hm.2021.104183. 
scoring by the opponent [6]; this action is more evident in teams of medium or low level $[9,10]$. Serrano et al. [11] found, in a study of the Spanish league, a decrease in the occurrence of goal defences over the $11 / 12$ to $16 / 17$ seasons, owing to the evolution of football, as well as the strategies adopted by the teams. According to White et al. [12], it seems evident that the quality of the opposition influences the occurrence of the goalkeeper's defensive intervention types. Other forms of goalkeeper's defensive intervention that have occurred with great frequency are the exit of the ball to the crossing [13] and catch the ball [14]. In defensive terms, the intervention zones of goalkeepers are located fundamentally within the penalty area $[6,15]$.

Sainz de Baranda et al. [9] and Liu et al. [10] observed that in high-level teams, the game with the goalkeeper's feet had a great relevance. Serrano et al. [11] reported that in La Liga, the prevalence of goalkeeper's passes increased throughout the editions of the competition. Nagy Soares et al. [13] verified a great incidence of replacement/passes with the feet in goalkeepers of the Paulista championship. In a study which analysed the actions of Neuer and Romero in the 2014 World Cup, it was found that the goalkeepers had high values of pass effectiveness with the hand and foot [16]. Among goalkeepers aged 14-16 years, a great effectiveness of passing was demonstrated, and there were behaviour patterns in these actions with the foot and hands [15]. The goalkeeper's action with their feet, after recovery of the ball, is essential to change the centre of the game to areas of lower pressure of the opponent [17]. Goalkeeper's pass is preferably made for defensive sidelines, as well as defensive and offensive midfield areas $[15,18]$.

Given this, and since there is still a vast field to investigate in this object of study, our goal is to examine the defensive and offensive actions in elite young football goalkeepers.

\section{Material and methods}

\section{Design}

The design of the research considered the procedures of observational methodology. Observational methodology allows the explanation of behaviours (goalkeepers' technical-tactical actions) in the context in which they develop (soccer game) [19]. In order to observe the offensive and defensive technical-tactical actions of goalkeepers, perceptive behaviours were codified by using non-standardized instruments [20]. The data were collected in the context in which the behaviours develop, which favours the ecological validity [21]. The observational design of our study is ideographic (participating goalkeeper), follow-up (study conducted throughout the season) and multidimensional (behaviour actions categorized in accordance with various response levels) [19].

\section{Participants}

Three U-17 goalkeepers participated in our study. The goalkeepers belonged to one of the most relevant teams in youth football training in Portugal and in the world. They competed in the Portuguese National Championship U-17, had an average age of 16.6 years and 8 years of experience, and were international for the national team of Portugal. Thirty games were observed, corresponding to the total sports season (goalkeeper A: 10 games; goalkeeper B: 12 games, and goalkeeper C: 8 games).

The observational sample consisted of defensive technical-tactical actions $(n=225)$ and offensive technical-tactical actions $(n=296)$.

\section{Observational instrument}

In order to analyse the technical-tactical defensive and offensive actions, we built and validated 2 observational instruments: the observation system of defensive technical-tactical actions and the observation system of offensive technical-tactical actions.

The process of the design and validation of the instruments considered the steps described by Brewer and Jones [22] and Fernandes et al. [23]. In the $1^{\text {st }}$ step, a literature review was carried out and instruments already constructed for other investigations were examined. Taking into account the variables already assumed in the construction of other instruments, as well as the observation of games, we began to build our instrument. In the $2^{\text {nd }}$ phase, the criteria and categories related to the offensive and defensive technicaltactical actions of goalkeepers were listed. The concepts concerning the categories and subcategories of our observational instrument were defined on the basis of the literature review performed previously. Observations were also made with the aim of verifying the occurrence of a new conduct in relation to those already listed. These steps aimed to ensure that the instrument constructed was exclusive and exhaustive. In the $3^{\text {rd }}$ phase, content was validated with experts. The preliminary versions of the observation systems were analysed by $5 \mathrm{PhD}$ professors in sports sciences and by 5 goalkeeper coaches (grade II and III, experience in the Por- 
Table 1. Observation system of defensive technicaltactical actions of goalkeepers

\begin{tabular}{ll}
\hline Criterion & Category \\
\hline & Crossing \\
Intervention form & Goal defence \\
& Get pieces \\
& $1 \times 1$ shot \\
& $1 \times 1$ divided \\
& Frontal attack \\
& Action as last defence \\
& High lateral drop deviation \\
& Deviation lateral creep \\
& Block \\
& Deviation to punch \\
& High deviation \\
& Enchase \\
& High reception \\
Technical action & High lateral fall reception \\
& Reception lateral fall creeping \\
& Creeping interception \\
\hline Form of execution of & Feet \\
the technical action & Chest \\
& Fists \\
& Head \\
\hline End action field zones & Field zones 1-10 \\
& \\
&
\end{tabular}

tuguese league and Portuguese national team). The instruments were sent to the experts, and an evaluation with suggestions for improvement was requested. The evaluation made by experts resulted in minor adjustments in the observation systems. After this phase, the observers were trained. Next, the intra- and interobserver reliability was analysed, a fundamental aspect of the observational methodology, in order to ensure the quality of the data [24]. To test reliability, we used Cohen's kappa [25] agreement measure. In the observation system of offensive technical-tactical actions, we recorded inter-observer reliability values of $k>0.82$ and intra-observer reliability values of $k>0.84$. In the observation system of defensive technical-tactical actions, we recorded inter-observer reliability values of $k>0.87$ and intra-observer reliability values of $k>0.81$.

The observation system of defensive technical-tactical actions of goalkeepers is constituted by 4 criteria and 34 categories (Table 1, Figure 1).

The observation system of offensive technical-tactical actions of goalkeepers is constituted by 6 criteria and 50 categories (Table 2, Figure 2).
Table 2. Observation system of offensive technicaltactical actions of goalkeepers

\begin{tabular}{|c|c|}
\hline Criterion & Category \\
\hline $\begin{array}{l}\text { How the ball reached } \\
\text { the goalkeeper }\end{array}$ & $\begin{array}{l}\text { Delay } \\
\text { Opponent's action } \\
\text { Rules }\end{array}$ \\
\hline Start action field zones & Field zones $1-12$ \\
\hline Technical action & $\begin{array}{l}\text { Short pass with } 2 \text { touches } \\
\text { Short hand replacement } \\
\text { Long hand replacement } \\
\text { Short replacement with feet } \\
\text { Long replacement with feet } \\
\text { Goalkeeper kick } \\
\text { Long pass at } 1^{\text {st }} \text { touch } \\
\text { Long pass at } 2^{\text {nd }} \text { touch } \\
\text { Long goal kick } \\
\text { Short goal kick } \\
\text { Short pass at } 1^{\text {st }} \text { touch } \\
\text { Ball conducting }+ \text { short pass } \\
\text { Ball conducting }+ \text { long pass } \\
\text { Dribbling/simulation }+ \text { short pass } \\
\text { Dribbling/simulation }+ \text { long pass } \\
\text { Short free kick } \\
\text { Long free kick }\end{array}$ \\
\hline Tactical decision & $\begin{array}{l}\text { Positional attack } \\
\text { Fast attack } \\
\text { Counterattack }\end{array}$ \\
\hline End of technical action & $\begin{array}{l}\text { Intercepted ball } \\
\text { Maintenance of ball possession } \\
\text { Ball out }\end{array}$ \\
\hline End action field zones & Field zones 1-12 \\
\hline
\end{tabular}

\section{Procedures}

The images were recorded with a camera (Sony HD - HDCR - CX240 9.2 mega pixels) placed on a tripod. The camera was positioned at a high level, with an open angle, so that it was always possible to identify the start of the play and the final goalkeeper's action. After the images were edited, the codification of defensive and offensive technical-tactical actions was implemented with the Lince ${ }^{\circledR}$ program [26].

\section{Data analysis}

Data analysis was performed with the Microsoft Excel $^{\circledast}$ computer program. In accordance with the observational study design, a descriptive analysis (percentage, mean, and standard deviation) was performed and a comparison between the 3 moments of the Portuguese National Championship U-17 was executed 


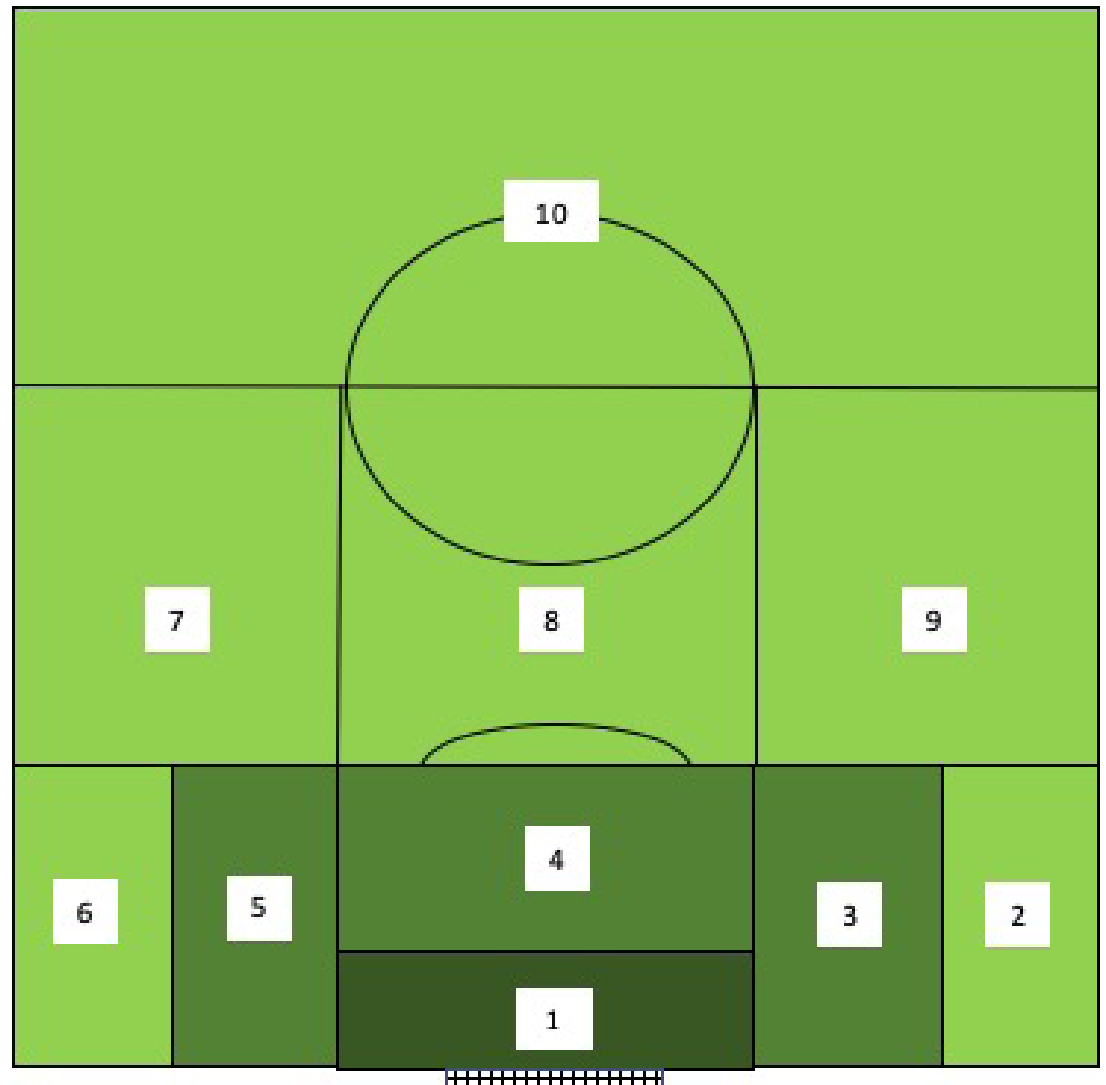

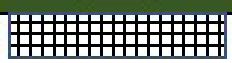

Figure 1. Schematic representation of defensive technical-tactical actions (adapted from Lapresa et al. [15])

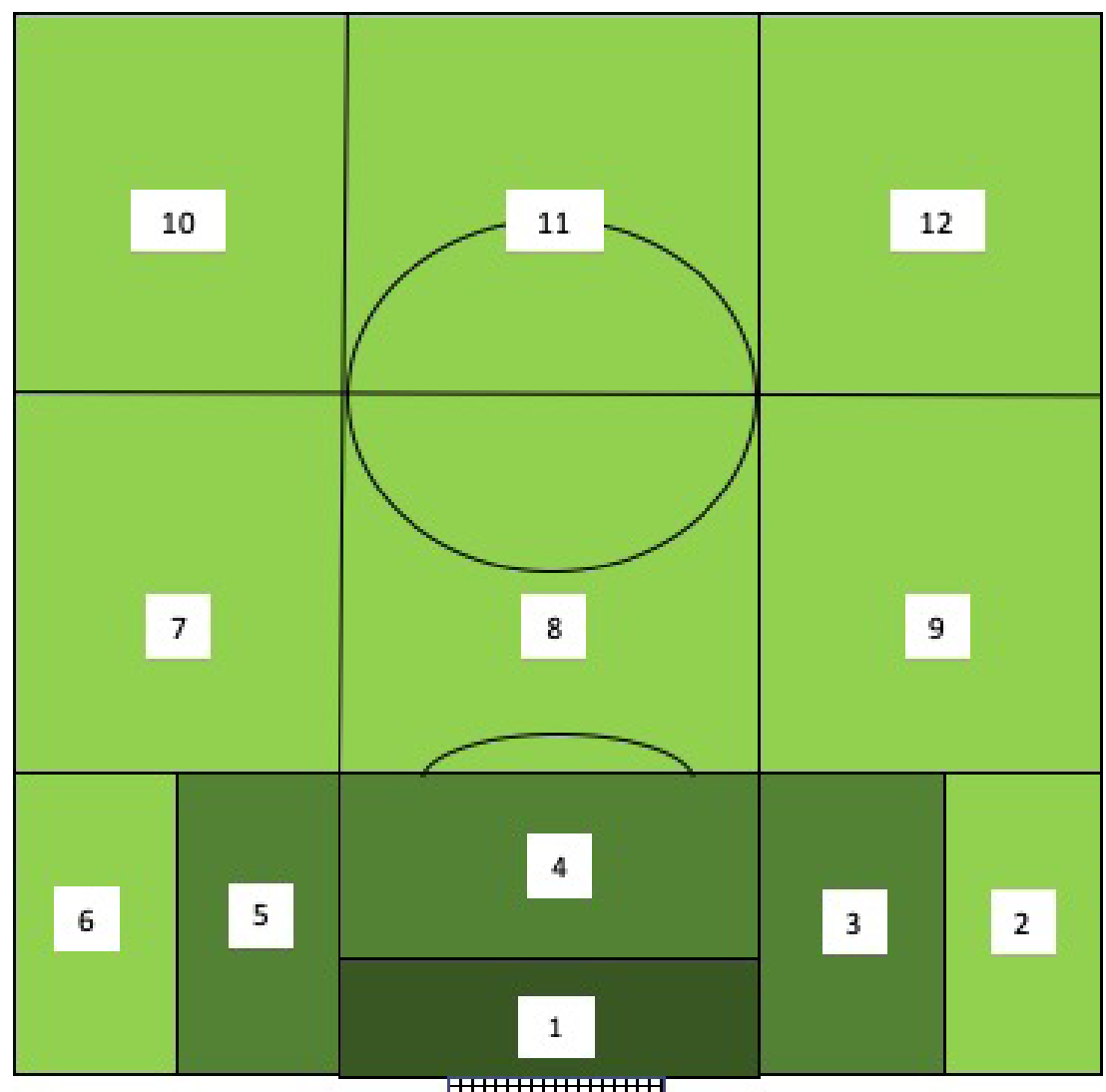

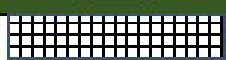

Figure 2. Schematic representation of offensive technical-tactical actions (adapted from Lapresa et al. [15]) 


\section{HUMAN MOVEMENT}

J. Santos, P.M. Sousa, V. Pinheiro, F.J. Santos, Analysis of goalkeepers' actions

by using the Kruskal-Wallis test $(p<0.05)$ [19], with the consideration that the distribution normality was not guaranteed.

\section{Ethical approval}

The research related to human use has complied with all the relevant national regulations and institutional policies, has followed the tenets of the Declaration of Helsinki [27], and has been approved by the Scientific Council of the Higher Institute of Educational Sciences.

\section{Informed consent}

Informed consent has been obtained from all individuals included in this study and their legal guardians.

\section{Results}

The results presented are related to the analysis of the goalkeepers' technical-tactical actions during the 3 championship phases. Table 3 illustrates the results of defensive technical-tactical actions and Table 4 depicts the results of offensive technical-tactical actions.

In Table 3, we can see that the main defensive action of the goalkeeper, with reference to the intervention form, was the goal defence $(n=76 ; 25.33 \pm 8.14)$. However, we also verified many occurrences of goal exit, more evident in the $2^{\text {nd }}$ and $3^{\text {rd }}$ phase.

Table 3. Number of goalkeepers' defensive actions

\begin{tabular}{|c|c|c|c|c|c|c|c|c|}
\hline \multirow{2}{*}{ Criterion } & \multirow{2}{*}{ Category } & \multicolumn{3}{|c|}{ Phase 1 Phase 2 Phase 3} & \multirow{2}{*}{$p$} & \multirow{2}{*}{ Sum } & \multirow{2}{*}{$\%$} & \multirow{2}{*}{$M \pm S D$} \\
\hline & & $n$ & $n$ & $n$ & & & & \\
\hline \multirow{4}{*}{ Intervention form } & Crossing & 4 & 20 & 11 & 0.07 & 35 & 15.56 & $11.67 \pm 8.02$ \\
\hline & Goal defence & 16 & 29 & 31 & 0.54 & 76 & 33.78 & $25.33 \pm 8.14$ \\
\hline & Set pieces & 2 & 28 & 13 & 0.05 & 43 & 19.11 & $14.33 \pm 13.05$ \\
\hline & Goal exit & 4 & 33 & 34 & 0.24 & 71 & 31.56 & $23.67 \pm 17.04$ \\
\hline \multirow{14}{*}{ Technical action } & $1 \times 1$ shot & 1 & 0 & 4 & 0.10 & 5 & 2.22 & $1.67 \pm 2.08$ \\
\hline & $1 \times 1$ divided & 0 & 10 & 9 & 0.15 & 19 & 8.44 & $6.33 \pm 5.51$ \\
\hline & Frontal attack & 4 & 9 & 10 & 0.37 & 23 & 10.22 & $7.67 \pm 3.21$ \\
\hline & Action as last defence & 3 & 7 & 4 & 0.74 & 14 & 6.22 & $4.67 \pm 2.08$ \\
\hline & High lateral drop deviation & 2 & 9 & 8 & 0.43 & 19 & 8.44 & $6.33 \pm 3.79$ \\
\hline & Deviation lateral creep & 1 & 3 & 3 & 0.42 & 7 & 3.11 & $2.33 \pm 1.15$ \\
\hline & Block & 6 & 10 & 10 & 0.14 & 26 & 11.56 & $8.67 \pm 2.31$ \\
\hline & Deviation to punch & 1 & 26 & 14 & 0.03 & 41 & 18.22 & $13.67 \pm 12.50$ \\
\hline & High deviation & 2 & 5 & 3 & 0.19 & 10 & 4.44 & $3.33 \pm 1.53$ \\
\hline & Enchase & 1 & 12 & 15 & 0.05 & 28 & 12.44 & $9.33 \pm 7.37$ \\
\hline & High reception & 5 & 15 & 7 & 0.23 & 27 & 12 & $9 \pm 5.29$ \\
\hline & High lateral fall reception & 0 & 1 & 0 & 0.43 & 1 & 0.44 & $0.33 \pm 0.58$ \\
\hline & Reception lateral fall creeping & 0 & 2 & 2 & 0.10 & 4 & 1.78 & $1.33 \pm 1.15$ \\
\hline & Creeping interception & 0 & 1 & 0 & 0.43 & 1 & 0.44 & $0.33 \pm 0.57$ \\
\hline \multirow{5}{*}{$\begin{array}{l}\text { Form of execution } \\
\text { of the technical } \\
\text { action }\end{array}$} & 1 hand & 1 & 14 & 10 & 0.10 & 25 & 11.11 & $8.33 \pm 6.65$ \\
\hline & 2 hands & 21 & 59 & 57 & 0.07 & 137 & 60.89 & $45.66 \pm 21.38$ \\
\hline & Feet & 2 & 10 & 6 & 0.31 & 18 & 8 & $6 \pm 4$ \\
\hline & Chest & 1 & 1 & 2 & 0.42 & 4 & 1.78 & $1.33 \pm 0.57$ \\
\hline & Fists & 1 & 26 & 14 & 0.03 & 41 & 18.22 & $13.66 \pm 12.50$ \\
\hline \multirow{10}{*}{$\begin{array}{l}\text { End action field } \\
\text { zones }\end{array}$} & 1 & 12 & 80 & 59 & 0.07 & 151 & 67.11 & $50.33 \pm 34.81$ \\
\hline & 2 & 0 & 0 & 0 & 1.00 & 0 & 0. & $0 \pm 0$ \\
\hline & 3 & 3 & 7 & 11 & 0.09 & 21 & 9.33 & $7 \pm 4$ \\
\hline & 4 & 6 & 9 & 8 & 0.07 & 23 & 10.22 & $7.66 \pm 1.52$ \\
\hline & 5 & 3 & 7 & 7 & 0.62 & 17 & 7.56 & $5.66 \pm 2.30$ \\
\hline & 6 & 0 & 0 & 0 & 1.00 & 0 & 0 & $0 \pm 0$ \\
\hline & 7 & 0 & 1 & 2 & 0.67 & 3 & 1.33 & $1 \pm 1$ \\
\hline & 8 & 2 & 3 & 1 & 0.32 & 6 & 2.67 & $2 \pm 1$ \\
\hline & 9 & 0 & 3 & 1 & 0.14 & 4 & 1.78 & $1.33 \pm 1.52$ \\
\hline & 10 & 0 & 0 & 0 & 1.00 & 0 & 0 & $0 \pm 0$ \\
\hline
\end{tabular}

Bold denotes actions with the most frequent occurrence 
Table 4. Number of goalkeepers' offensive actions

\begin{tabular}{|c|c|c|c|c|c|c|c|c|}
\hline \multirow{2}{*}{ Criterion } & \multirow{2}{*}{ Category } & \multicolumn{3}{|c|}{ Phase 1 Phase 2 Phase 3} & \multirow{2}{*}{$p$} & \multirow{2}{*}{ Sum } & \multirow{2}{*}{$\%$} & \multirow{2}{*}{$M \pm S D$} \\
\hline & & $\mathrm{n}$ & $\mathrm{n}$ & $\mathrm{n}$ & & & & \\
\hline \multirow{3}{*}{$\begin{array}{l}\text { How the ball } \\
\text { reached the } \\
\text { goalkeeper }\end{array}$} & Delay & 6 & 55 & 54 & 0.07 & 115 & 38.85 & $38.33 \pm 28.01$ \\
\hline & Opponent's action & 8 & 46 & 38 & 0.31 & 92 & 31.08 & $30.67 \pm 20.03$ \\
\hline & Rules & 7 & 34 & 48 & 0.04 & 89 & 30.07 & $29.67 \pm 20.84$ \\
\hline \multirow{12}{*}{$\begin{array}{l}\text { Start action field } \\
\text { zones }\end{array}$} & 1 & 7 & 31 & 48 & 0.06 & 86 & 29.05 & $28.7 \pm 20.60$ \\
\hline & 2 & 0 & 4 & 5 & 0.04 & 9 & 3.04 & $3 \pm 2.65$ \\
\hline & 3 & 2 & 18 & 14 & 0.07 & 34 & 11.49 & $11.3 \pm 8.33$ \\
\hline & 4 & 7 & 42 & 34 & 0.13 & 83 & 28.04 & $27.7 \pm 18.34$ \\
\hline & 5 & 0 & 5 & 5 & 0.19 & 10 & 3.38 & $3.3 \pm 2.89$ \\
\hline & 6 & 0 & 3 & 5 & 0.11 & 8 & 2.70 & $2.7 \pm 2.52$ \\
\hline & 7 & 3 & 13 & 7 & 0.32 & 23 & 7.77 & $7.7 \pm 5.03$ \\
\hline & 8 & 0 & 16 & 16 & 0.05 & 32 & 10.81 & $10.7 \pm 9.24$ \\
\hline & 9 & 2 & 3 & 6 & 0.12 & 11 & 3.72 & $3.7 \pm 2.08$ \\
\hline & 10 & 0 & 0 & 0 & 1.00 & 0 & 0 & $0 \pm 0$ \\
\hline & 11 & 0 & 0 & 0 & 1.00 & 0 & 0 & $0 \pm 0$ \\
\hline & 12 & 0 & 0 & 0 & 1.00 & 0 & 0 & $0 \pm 0$ \\
\hline \multirow{13}{*}{ Technical action } & Short pass with 2 touches & 3 & 22 & 18 & 0.27 & 43 & 14.58 & $14.33 \pm 10.02$ \\
\hline & Short hand replacement & 4 & 28 & 18 & 0.09 & 50 & 16.95 & $16.67 \pm 12.06$ \\
\hline & Long hand replacement & 2 & 10 & 8 & 0.37 & 20 & 6.78 & $6.67 \pm 4.16$ \\
\hline & Goalkeeper kick & 3 & 6 & 7 & 0.57 & 16 & 5.42 & $5.33 \pm 2.08$ \\
\hline & Long pass at $1^{\text {st }}$ touch & 1 & 9 & 17 & 0.04 & 27. & 9.15 & $9 \pm 8$ \\
\hline & Long pass at $2^{\text {nd }}$ touch & 2 & 9 & 10 & 0.31 & 21 & 7.12 & $7 \pm 4.36$ \\
\hline & Long goal kick & 5 & 14 & 33 & 0.09 & 52 & 17.63 & $17.33 \pm 14.29$ \\
\hline & Short goal kick & 1 & 10 & 8 & & 19 & 6.44 & $6.33 \pm 4.73$ \\
\hline & Short pass at $1^{\text {st }}$ touch & 0 & 9 & 3 & 0.05 & 12 & 4.07 & $4 \pm 4.58$ \\
\hline & Ball conducting + short pass & 0 & 3 & 2 & 0.19 & 5 & 1.69 & $1.67 \pm 1.53$ \\
\hline & Ball conducting + long pass & 0 & 7 & 8 & 0.11 & 15 & 5.08 & $5 \pm 4.36$ \\
\hline & Short free kick & 0 & 2 & 2 & 0.41 & 4 & 1.36 & $1.33 \pm 1.15$ \\
\hline & Long free kick & 0 & 6 & 5 & 0.07 & 11 & 3.73 & $3.67 \pm 3.21$ \\
\hline \multirow{3}{*}{ Tactical decision } & Positional attack & 16 & 114 & 128 & 0.05 & 258 & 87.46 & $86 \pm 61.02$ \\
\hline & Fast attack & 2 & 16 & 9 & 0.24 & 27 & 9.15 & $9 \pm 7$ \\
\hline & Counterattack & 3 & 5 & 2 & 0.95 & 10 & 3.39 & $3.33 \pm 1.53$ \\
\hline \multirow{3}{*}{$\begin{array}{l}\text { End of technical } \\
\text { action }\end{array}$} & Intercepted ball & 8 & 18 & 36 & 0.05 & 62 & 21.23 & $20.67 \pm 14.19$ \\
\hline & Maintenance of ball possession & 13 & 112 & 97 & 0.07 & 222 & 76.03 & $74 \pm 53.36$ \\
\hline & Ball out & 0 & 3 & 5 & 0.11 & 8 & 2.74 & $2.67 \pm 2.52$ \\
\hline \multirow{12}{*}{$\begin{array}{l}\text { End action field } \\
\text { zones }\end{array}$} & 1 & 0 & 0 & 0 & 1.00 & 0 & 0 & $0 \pm 0$ \\
\hline & 2 & 2 & 6 & 4 & 0.53 & 12 & 4.11 & $4 \pm 2$ \\
\hline & 3 & 1 & 8 & 1 & 0.42 & 10 & 3.42 & $3.33 \pm 4.04$ \\
\hline & 4 & 0 & 0 & 0 & 1.00 & 0 & 0 & $0 \pm 0$ \\
\hline & 5 & 1 & 6 & 7 & 0.18 & 14 & 4.79 & $4.67 \pm 3.21$ \\
\hline & 6 & 0 & 6 & 4 & 0.15 & 10 & 3.42 & $3.33 \pm 3.06$ \\
\hline & 7 & 1 & 23 & 15 & 0.19 & 39 & 13.36 & $13 \pm 11.14$ \\
\hline & 8 & 2 & 24 & 17 & 0.29 & 43 & 14.73 & $14.33 \pm 11.24$ \\
\hline & 9 & 6 & 20 & 26 & 0.04 & 52 & 17.81 & $17.33 \pm 10.26$ \\
\hline & 10 & 2 & 18 & 28 & 0.04 & 48 & 16.44 & $16 \pm 13.11$ \\
\hline & 11 & 6 & 9 & 13 & 0.20 & 28 & 9.59 & $9.33 \pm 3.51$ \\
\hline & 12 & 0 & 13 & 23 & 0.03 & 36 & 12.33 & $12 \pm 11.53$ \\
\hline
\end{tabular}

Bold denotes actions with the most frequent occurrence 
As for the technical action, we found that the goalkeepers intervened most through the deviation to punch $(n=41 ; 13.67 \pm 12.50)$, followed by enchase $(n=28$; $9.33 \pm 7.37)$ and high reception $(n=27 ; 9.00 \pm 5.29)$. It was evident that in the 3 phases of the competition, there were statistically significant differences in the technical action of deviation to punch ( $p=0.03$ ).

The form of execution of the preferred technical action was with 2 hands $(n=137 ; 45.66 \pm 21.38)$ and fists $(n=41 ; 13.66 \pm 12.50)$. It was in the form of technical execution with the fists that we verified statistically significant differences in the 3 phases $(p=$ 0.03).

Most defensive actions by the goalkeepers happened in zone 1 ( $n=151 ; 50.33 \pm 34.81)$, followed by zone 4 $(n=23 ; 7.66 \pm 1.52)$ and $3(n=21 ; 7 \pm 4)$.

In the offensive technical-tactical actions (Table 4), we found that the ball reached the goalkeeper mostly through the delayed pass $(n=115 ; 38.33 \pm 28.01)$, followed by opponent's action ( $n=92 ; 30.67 \pm 20.03$ ) and rules $(n=89 ; 29.67 \pm 20.84)$. By checking the 3 phases of the competition, we observed that there were statistically significant differences in how the ball reached the goalkeeper through the rules $(p=0.04)$.

The goalkeepers started their offensive actions most often in zones 1 ( $n=86 ; 28.7 \pm 20.60), 4(n=83 ; 27.7$ $\pm 18.34)$, and $3(n=34 ; 11.3 \pm 8.33)$. In the championship phase 2 , we verified a higher incidence of the beginning of offensive actions in zone 4 . In the start action zone 2 , there were significant differences between the 3 phases $(p=0.04)$.

The most often recorded technical actions were long goal kick ( $n=52 ; 17.33 \pm 14.29)$, short hand replacement ( $n=50 ; 16.67 \pm 12.06)$, and short pass with 2 touches $(n=43 ; 14.33 \pm 10.02)$. It was verified that in phase 2 , there was a more frequent occurrence of short replacement with the hand and short pass with 2 touches, compared with the long goal kick. In the long pass at the $1^{\text {st }}$ touch, significant differences were observed comparing the 3 phases $(p=0.04)$.

It was revealed that the goalkeepers most often chose to start the offensive team construction by positional attack $(n=258 ; 86 \pm 61.02)$.

In most of the occurrences, the technical action performed resulted in the maintenance of the ball possession $(n=222 ; 74 \pm 53.36)$.

The final zones of action were preferably zone $9(n=$ $52 ; 17.33 \pm 10.26), 10(n=48 ; 16 \pm 13.11)$, and 8 $(n=43 ; 14.33 \pm 11.24)$. Comparing the 3 phases of the competition, we found significant differences in the final action zones $9(p=0.04), 10(p=0.04)$, and 12 $(p=0.03)$.

\section{Discussion}

Our study aimed to examine the defensive and offensive technical-tactical actions of goalkeepers who competed in the Portuguese National Championship U-17. The recently conducted studies allow us to verify that much can be investigated in the field of young football goalkeepers [2, 12]. It is in this sense that our discussion will be based on some research with professional goalkeepers, although a study by Lapresa et al. [15] provides important results related to young goalkeepers' actions. We cannot overlook the fact that the goalkeepers observed belong to an elite club and that they are in the stage of entry into professional football. Although our study did not verify the effectiveness of technical-tactical actions, it characterizes, through notational analysis, offensive and defensive actions of elite young goalkeepers, providing relevant information on the game and the players' action in the game, as well as offering specific coaches important indicators related to training their goalkeepers [4, 6, 28]. Our results imply that in the $2^{\text {nd }}$ and $3^{\text {rd }}$ championship phases, where the goalkeepers begin to face the highest-level opponents, the technical-tactical defensive and offensive actions increase. It is important for goalkeeper coaches to adjust their training plans to the moments and contexts of the competition [2], since in the competitive context of formation, the game may not be creating all the problem situations that allow the evolution of goalkeepers.

In the analysis of defensive actions, we found that the largest number of occurrences referred to the goal defence, a fact that agrees with other studies $[6,10]$. However, we can also see a large impact, in the forms of goalkeeper's intervention, of exit from the goal. De Magalhães Berto and Oliveira Magalhães [28], among U-15 goalkeepers competing in the state championship, also reported many occurrences of goal exit. In high-level goalkeepers, the importance of low and high goal exits, having a high level of effectiveness, was verified $[14,16]$. Among U-16 goalkeepers, there were also many interventions in this form, constituting a behaviour pattern within the penalty area [15]. One of the surprising results in our study lies in the defensive technical action of deviation to punch, having a strong incidence and used by goalkeepers with great effectiveness [14]. This result also explains the number of goalkeepers' interventions in set pieces, which promote crossings to the area (corners and free side), moments important in the game of football for obtaining the goal [29]. This should lead coaches to consider the significance of training the deviation to punch technique in 
the youth age groups [15]. Other defensive technical actions usually used by the goalkeepers observed were the enchase and high reception. Lapresa et al. [15] found that the aerial game had much relevance for goalkeepers; however, they also observed a large percentage of ineffectiveness in the execution of this technical action. It should be noted that the way that the observed goalkeepers performed their technical actions was with both hands. We can also verify that most defensive actions occur within the penalty area [6].

As for the offensive actions, we reported that in many occurrences, the ball reached the goalkeeper by opponent action, which is line with goal defence, registered for the form of intervention of defensive actions. It should be noted that in phase 3 , the decisive stage of the championship, there was a decrease in occurrences of arrival of the ball through the action of opponents, owing to a greater defensive consistency and a concern with strategic aspects [11]. However, our study reveals that it is through the back pass of teammates that the ball reached preferably the goalkeeper. Barreira et al. [17] emphasize the importance of goalkeepers when, after recovery of the ball, in the variation of the centre of the game, placing with their feet the ball in areas of less pressure of the opponent. The most observed areas of starting offensive actions were the penalty area and the frontal zone outside the large area, which reflects the most used technical-tactical actions. We reported a higher frequency of short hand replacement, short pass with 2 touches, and long pass. There were also many occurrences of long goal kick, a result of ball outs by the final line. Studies have found a considerable incidence of the game with the feet in high-level teams [9-11, 13], which reveals the great importance of the goalkeeper in the offensive process of the team, implying a good ability to make short and long passes accurately, with both feet, since an offensive game can be built by any flank [2]. Another obvious fact in our study is the option of goalkeepers to put the ball back with their hands on a short pass. In a study by Marques Filho et al. [16], many occurrences of passes performed by hand were also verified. In our study, considering that the observed goalkeepers belong to a team competing for the national champion title, we found that the short replacement option was the most used. This is also evident for the pass with the foot, with a great effectiveness in the actions performed, since our study recorded that the team continued in ball possession. Szwarc et al. [14] indicated that goalkeepers were looking for effective play essentially to maintain possession. This shows that high-level teams often find their opponents, especially when they are of lesser value, performing a lower pressure start $[12,30]$. Our results demonstrate this, since there was a high incidence of passes to the defensive midfield areas, starting the positional attack of the team in these areas. Studies are in line with what we have recorded $[15,18]$, at the same time verifying that goalkeepers also use the long pass for middle-field offensive zones, which was confirmed with our goalkeepers for side flank zones of the attacking midfield.

Our investigation was carried out with 3 goalkeepers from a U-17 team. Further research is needed with more participants, of different age groups, and belonging to teams of different levels. T-pattern analysis, sequential analysis, and polar coordinate analysis can be used within the observational methodology in order to achieve a better understanding of goalkeepers' actions in the defensive and offensive process.

\section{Conclusions}

In the defensive process, the goalkeepers intervened primarily to defend the goal in the zone within the small area, using techniques of deviation to punch, enchase, and high reception.

In the offensive process, the participation of a goalkeeper resulted from late passes of teammates, showing fundamental technical actions with the feet in the offensive construction of the team, preferably to the side flanks. The short replacement technique with the hand proved relevant to the team positional attack construction.

During the different phases of the championship, it was possible to verify some changes in the technicaltactical actions of the observed goalkeepers, which may be related to increased quality of opponents, as well as to the team's game model; to the team strategy and the opponent strategy.

This investigation contributes to a greater knowledge of goalkeepers' actions in the defensive and offensive moment, and thus provides more key data to the planning of specific training.

\section{Funding}

Portuguese Foundation for Science and Technology, I.P., grant/award number UIDP/04748/2020.

\section{Disclosure statement}

No author has any financial interest or received any financial benefit from this research.

\section{Conflict of interest}

The authors state no conflict of interest. 


\section{References}

1. O’Donoghue P. The use of feedback videos in sport. Int J Perform Anal Sport. 2006;6(2):1-14; doi: 10.1080/ 24748668.2006.11868368.

2. West J. A review of the key demands for a football goalkeeper. Int J Sports Sci Coach. 2018;13(6):1215-1222; doi: 10.1177/1747954118787493.

3. Martin D, Swanton A, Bradley J, McGrath D. The use, integration and perceived value of performance analysis to professional and amateur Irish coaches. Int J Sports Sci Coach. 2018;13(4):520-532; doi: 10.1177/ 1747954117753806.

4. Sampaio J, Maçãs V. Measuring tactical behaviour in football. Int J Sports Med. 2012;33(5):395-401; doi: 10.1055/s-0031-1301320.

5. Padulo J, Haddad M, Ardigò LP, Chamari K, Pizzolato F. High frequency performance analysis of professional soccer goalkeepers: a pilot study. J Sports Med Phys Fitness. 2015;55(6):557-562.

6. Sainz De Baranda P, Ortega E, Palao JM. Analysis of goalkeepers' defence in the World Cup in Korea and Japan in 2002. Eur J Sport Sci. 2008;8(3):127-134; doi: 10.1080/17461390801919045.

7. Szwarc A, Jaszczur-Nowicki J, Aschenbrenner P, Zasada M, Padulo J, Lipinska P. Motion analysis of elite Polish soccer goalkeepers throughout a season. Biol Sport. 2019;36(4):357-363; doi:10.5114/biolsport.2019.88758.

8. Hughes M, James N. Notational analysis of soccer. In: Milanović D, Prot F (eds.), Proceedings book: $5^{\text {th }}$ International Scientific Conference on Kinesiology "Kinesiology research trends and applications”. Zagreb: Faculty of Kinesiology, University ofZagreb; 2008; 644-660.

9. Sainz de Baranda P, Adán L, García-Angulo A, GómezLópez M, Nikolic B, Ortega-Toro E. Differences in the offensive and defensive actions of the goalkeepers at Women's FIFA World Cup 2011. Front Psychol. 2019; 10:223; doi: 10.3389/fpsyg.2019.00223.

10. Liu H, Gómez MA, Lago-Peñas C. Match performance profiles of goalkeepers of elite football teams. Int J Sports Sci Coach. 2015;10(4):669-682; doi: 10.1260/ 1747-9541.10.4.669.

11. Serrano C, Paredes-Hernández V, Sánchez-Sánchez J, Gallardo-Pérez J, Da Silva R, Porcel D, et al. The team's influence on physical and technical demands of elite goalkeepers in LaLiga: a longitudinal study in professional soccer. Res Sports Med. 2019;27(4):424-438; doi: 10.1080/15438627.2018.1555755.

12. White A, Hills SP, Cooke CB, Batten T, Kilduff LP, Cook CJ, et al. Match-play and performance test responses of soccer goalkeepers: a review of current literature. Sports Med. 2018;48(11):2497-2516; doi: 10.1007/ s40279-018-0977-2.

13. Nagy Soares V, e Cren Chiminazzo JG, Tramontina Bergonsi J, Teixeira Fernandes P. Analysis of the technical actions of a football goalkeeper: a preliminary study [in Portuguese]. Rev Bras Futsal Futebol. 2018; 10(38):307-313.
14. Szwarc A, Lipińska P, Chamera M. The efficiency model of goalkeeper's actions in soccer. Balt J Health Phys Act. 2010;2(2):132-138; doi: 10.2478/v10131-0013-x.

15. Lapresa D, Chivite Navascués J, Arana Idiakez J, Anguera MT, Barbero Cadirat JR. Analysis of the effectiveness of under-16 football goalkeepers. Apunts Educ Fis Deporte. 2018;131(1):60-79; doi: 10.5672/apunts. 2014-0983.es.(2018/1).131.05.

16. Marques Filho CV, de Carvalho Silva L, Ramirez Lizana CJ, Bagiotto Bettega O, Scaglia AJ, Galatti LR. Neuer vs. Romero: technical-tactical comparison between the goalkeepers of the finalists of the FIFA World Cup 2014 [in Portuguese]. Rev Bras Futsal Futebol. 2018; 10(38):347-353.

17. Barreira D, Garganta J, Machado JC, Anguera MT. Effects of ball recovery on top-level soccer attacking patterns of play. Rev Bras Cineantropom Desempenho Hum. 2014;16(1):36-46; doi: 10.5007/1980-0037.2014 v16n1p36.

18. Seaton M, Campos J. Distribution competence of a football clubs goalkeepers. Int J Perform Anal Sport. 2011; 11(2):314-324; doi:10.1080/24748668.2011.11868551.

19. Anguera MT, Blanco-Villaseñor A, Losada JL, Portell M. Guidelines for designing and conducting a study that applies observational methodology [in Spanish]. Anu Psicol. 2018;48(1):9-17; doi: 10.1016/j.anpsic.2018.02. 001.

20. Chacón-Moscoso S, Anguera MT, Sanduvete-Chaves S, Losada JL, Lozano-Lozano JA, Portell M. Methodological quality checklist for studies based on observational methodology (MQCOM). Psicothema. 2019;31(4):458464; doi: 10.7334/psicothema2019.116.

21. Portell M, Anguera MT, Hernández-Mendo A, Jonsson GK. Quantifying biopsychosocial aspects in everyday contexts: an integrative methodological approach from the behavioral sciences. Psychol Res Behav Manag. 2015;8:153-160; doi: 10.2147/PRBM.S82417.

22. Brewer CJ, Jones RL. A five-stage process for establishing contextually valid systematic observation instruments: the case of rugby union. Sport Psychol. 2002; 16(2):138-159; doi: 10.1123/tsp.16.2.138.

23. Fernandes T, Camerino O, Garganta J, Pereira R, Barreira D. Design and validation of an observational instrument for defence in soccer based on the Dynamical Systems Theory. Int J Sports Sci Coach. 2019;14(2): 138-152; doi: 10.1177/1747954119827283.

24. Blanco Villaseñor Á, Castellano Paulis J, HernándezMendo A, Sánchez-López CR, Usabiaga O. Application of the generalizability theory in sport to study the validity, reliability and estimation of samples [in Spanish]. Rev Psicol Deporte. 2014;23(1):131-137.

25. Cohen J. A coefficient of agreement for nominal scales. Educ Psychol Meas. 1960;20(1):37-46; doi: 10.1177/ 001316446002000104.

26. Gabin B, Camerino O, Anguera MT, Castañer M. Lince: multiplatform sport analysis software. Procedia Soc Behav Sci. 2012;46:4692-4694; doi: 10.1016/j.sbspro. 2012.06.320. 
27. Harriss DJ, Atkinson G. Update - ethical standards in sport and exercise science research. Int J Sports Med. 2011;32(11):819-821; doi: 10.1055/s-0031-1287829.

28. De Magalhães Berto ES, Oliveira Magalhães FC. Quantitative analysis of the football goalkeeper's actions [in Portuguese]. Rev Bras Futsal Futebol. 2017;9(34):273281.

29. González-Ródenas J, López-Bondia I, Aranda-Malavés $R$, Tudela Desantes $\mathrm{A}$, Sanz-Ramírez E, Aranda Malaves R. Technical, tactical and spatial indicators related to goal scoring in European elite soccer. J Hum Sport Exerc. 2020;15(1):186-201; doi: 10.14198/jhse. 2020.151.17.

30. Santos PM, Lago-Penas C. Defensive positioning on the pitch in relation with situational variables of a professional football team during regaining possession. Hum Mov. 2019;20(2):50-56; doi: 10.5114/hm.2019.81019. 